\title{
USEFULNESS OF DIAGNOSTIC LAPAROSCOPY OVER CECT ABDOMEN IN ASSESSING OPERABILITY IN GASTROINTESTINAL MALIGNANCY
}

\author{
${ }^{1}$ Associate Professor, Department of Surgery, KIMS, KIIT, Bhubaneswar. \\ ${ }^{2}$ Associate Professor, Department of Surgery, KIMS, KIIT, Bhubaneswar. \\ 3Professor, Department of Surgical Oncology, AIIMS, Bhubaneswar. \\ ${ }_{4}^{4}$ Assistant Professor, Department of Surgery, KIMS, KIIT, Bhubaneswar. \\ ${ }_{5}^{5}$ Assistant Professor, Department of Radiology, KIMS, KIIT, Bhubaneswar. \\ ${ }^{6}$ Associate Professor, Department of Biotechnology, KIIT, Bhubaneswar.
}

Amaresh Mishra', Subrat Kumar Mohanty², Madhabananda Kar ${ }^{3}$, Sakti Prasad Sahoo 4 , Sanjeet Mishra ${ }^{5}$, Arttatrana Pal 6

\begin{abstract}
\section{BACKGROUND}

New advancement in CT scan has greatly helped the surgeons in accurately staging gastrointestinal malignancies and planning its treatment protocols. In this era of minimal invasive surgery, direct vision of the intraabdominal malignancies taking FNAC or biopsy of tumour and assessing its operability can avoid some of the shortcomings of CECT abdomen. It may further help in modifying the treatment protocol for a particular patient if the CECT finding does not match with that of biopsy report or direct laparoscopic assessment of tumour. Here the aim of the study was to find out the overall accuracy of diagnostic laparoscopy abdomen in assessing the operability in cases of gastrointestinal malignancies.
\end{abstract}

\section{METHODS}

This was a prospective study of total 40 patients with gastrointestinal malignancy, where all the patients were evaluated by CECT abdomen and found fit to undergo definite surgical procedure. All the patients were subjected to diagnostic and staging laparoscopy to assess the operability at Kalinga Institute of Medical Sciences between August 2012 and November 2014.

\section{RESULTS}

On preoperative diagnostic staging laparoscopy, it was found that out of 40 cases who were having CECT criteria of operability, 8 had metastatic disease, 8 had unresectable tumour due to local tumour ingrowth and one had benign disease on lap. Assisted tumour biopsy. Also palliative procedures like feeding jejunostomy in two patients with advanced cancer stomach.

\section{CONCLUSION}

Routine preoperative diagnostic and staging laparoscopy helped us in detecting advanced disease in significant no. of patient which otherwise was missed in CECT evaluation. Therefore, in our opinion it should be practiced routinely for staging GI malignancy either just before the planned surgery or as a separate diagnostic procedure. It should be added to the investigation modality to detect operability in GI malignancy.

\section{KEYWORDS}

Laparoscopy, Staging, Gastrointestinal Malignancy, Laparotomy, Imaging Modalities.

HOW TO CITE THIS ARTICLE: Mishra A, Mohanty SK, Kar M, et al. Usefulness of diagnostic laparoscopy over CECT abdomen in assessing operability in gastrointestinal malignancy. J. Evolution Med. Dent. Sci. 2016;5(56):3830-3835, DOI: $10.14260 /$ jemds/2016/877

\section{INTRODUCTION}

Surgical resection of patients with malignancies of the soft organs carries significant morbidity and mortality and many patients with advanced unresectable metastatic disease, palliation is all that can be offered.[1] Clinical staging is to accurately define the extent of disease, direct appropriate therapy and to avoid unnecessary interventions because nonsurgical palliation methods are now available mostly in all hospitals.[2]

Financial or Other, Competing Interest: None.

Submission 14-05-2016, Peer Review 09-06-2016,

Acceptance 14-06-2016, Published 12-07-2016.

Corresponding Author:

Dr. Madhabananda Kar,

Professor,

Department of Surgery,

KIMS, KIIT, Bhubaneswar-751024,

Odisha, India.

E-mail: madhabananda@gmail.com

DOI: $10.14260 /$ jemds $/ 2016 / 877$
Despite an increasingly sophisticated radiological diagnostic armamentarium, many patients with GI malignancy are diagnosed with unresectable or metastatic disease made at exploratory laparotomy.[2] However, those patients who do not require a palliative procedure, exploration confer little benefit and may be associated with significant morbidity and mortality affecting both the quality and duration of their survival.[2]

The potential to prevent a non-therapeutic laparotomy by means of accurate and less invasive staging is the driving force behind laparoscopic staging of GI malignancy. Laparoscopy is exalted as king of all surgical procedures, which play a complementary role in the staging of abdominal malignancy. Laparoscopic examination can visualize the primary tumour, identify small hepatic and peritoneal metastases, diagnose regional nodal metastases, can assess the tumour in growth along with the added advantages of short hospitalization, increased comfort, their rapid return to normal activities. [3] 
Despite the technical advances in CT scan/CECT, MRI and many other techniques, the diagnosis of small peritoneal deposits, small hepatic metastases, regional nodal metastases and local tumour in growth is frequently made during exploratory laparotomy.[4-7] With the rapid advancement in the instrumentation and technique in last two decades, laparoscopy has gained the wide acceptance as a new important modality in the evaluation of GI malignancy. Furthermore, diagnostic laparoscopy has been recommended as an important new staging modality and it is nearly as sensitive as an explorative laparotomy in detecting small peritoneal deposits and when combined with ultrasonography small liver metastases and local ingrowths can be diagnosed.[1] Biopsies can be taken under direct laparoscopic or ultrasound guidance and the procedurerelated morbidity and mortality are relatively low.[8-10] In the current study, our study aims to find out how helpful is laparoscopy in staging GI malignancy in comparison to CECT abdomen in diagnosis and staging of GI malignancies.

\section{PATIENTS AND METHODS}

This was a prospective study of GI malignancy patients, evaluated by diagnostic and staging laparoscopy between August 2012 and November 2014. Total 106 patients were presented with GI cancers and out of which 66 patients were diagnosed with inoperable disease and were excluded from the study. In the study group, only 40 patients (27 male and 13 female) including stomach $(\mathrm{n}=19)$, lower oesophagus $(n=1)$, cystic neoplasm of pancreas $(n=1)$, periampullary $(n=4)$, gallbladder $(n=4)$, colon $(n=4)$, rectum $(n=6)$, and benign $(n=1)$ were subjected to diagnostic laparoscopy in the immediate preop period. The mean age of presentation was 56.8 years (27-86 years) and maximum numbers of patients were in the age group of 61-70 years. Patients with non-GI tract cancers including gynaecological cancers, genitourinary cancers, retroperitoneal sarcoma, lymphoma, abdominal metastasis from non-GI cancers and metastatic cancers were excluded from the study group.

The priority of the study was to find out specificity and positive predictive value of diagnostic laparoscopy in diagnosis staging of GI malignancy in comparison to CECT evaluation alone. After a thorough preoperative evaluation such as clinical imaging and perioperative parameters, patients with suspected non-metastatic GI cancers were found resectable. Preoperative investigations included basic haemogram, chest X-ray, renal function test, liver function test, ultrasound scan of abdomen and CT scan of abdomen. For oesophageal tumours, ultrasonography combined with Doppler ultrasonography of the neck and abdomen, indirect laryngoscopy and bronchoscopy examinations were done when indicated. Patients with obstructive jaundice underwent an endoscopic retrograde cholangiopancreatography with insertion of an endoprosthesis and CT scans were frequently made in referring departments in our hospital. To verify vascular involvement, visceral angiography was performed in patients by Doppler ultrasound and CT angiography.

Preparation for surgery included preoperative pulmonary spirometer exercise, bowel preparation and antibiotics prophylaxis. Camera port was usually placed near the midline and two working ports were put on either lumbar regions and also at times additional ports were put anywhere as and when required. General inspection of peritoneal cavity and liver surface was done first and any suspicious lesions on liver or anywhere in the peritoneal surface including paraaortic nodes were biopsied. Lesser sac was entered in cases of upper GI malignancy. Biopsy proven metastases and tumour in growth were excluded from further surgical exploration. Patients with local tumour infiltration or vascular involvement were also excluded from surgery. In other patients found operable by laparoscopic evaluation were prepared for a single stage surgery. All patients received standard postoperative care that included antibiotics, preparation, analgesics, intravenous fluid, chest physiotherapy and prophylaxis for deep vein thrombosis. Study was approved by Institutional Review Board and Human Ethics Committee of the KIIT University, Bhubaneswar.

\section{RESULTS}

Between two consecutive years of our study period 106 patients were presented with GI cancers and out of which 66 patients were diagnosed with inoperable disease for various reasons (Table 1). Forty patients underwent diagnostic laparoscopy and subsequent open surgery in GI malignancies (Fig. 1). Out of forty patients, open surgery was avoided in 8 (20\%) including 6 patients with Carcinoma stomach and 2 patients with carcinoma gall bladder. After diagnostic laparoscopy, laparotomy was avoided in 8 (20\%) out of 40 patients including 6 patients with stomach cancer and 2 patients with gallbladder cancer because of disseminated disease with multiple peritoneal deposits (Fig. 2). No definitive procedure was done in these patients except laparoscopic feeding jejunostomy in 2 patients with locally advanced carcinoma stomach without ascites. Interestingly, one of these patients also had malrotation of gut. These patients were otherwise found fit for surgery after CECT abdomen. The benefits of laparoscopy over CECT in avoiding the unnecessary laparotomy has been depicted in (Table 2). Diagnostic laparoscopy also helped us in identifying additional information in certain cases. We used intraoperative FNAC in certain doubtful liver lesions without gross disseminated disease. In one patient with prepyloric growth stomach, there was a granulomatous lesion in segment VIII in liver (Fig. 3).

Intraoperative laparoscopy guided FNAC was negative for malignancy and open radical D2 gastrectomy was completed. In other two cases in stomach cancer and sigmoid colon, intraoperative FNAC was positive for malignancy in suspected liver lesions, so only palliative procedures like bypass loop gastrojejunostomy, jejunojejunostomy and sigmoid colectomy was done. We also had cirrhosis of liver (S1) and liver haemangioma (S2), detected in 2 patients each after diagnostic laparoscopic evaluation. These were unexpected findings affecting the postoperative outcomes, particularly in cirrhosis of liver. In our series, there was no mortality due to added surgical stress in diagnostic staging laparoscopy.

After diagnostic laparoscopy, all the patients found fit had undergone laparotomy in the same sitting. Diagnostic laparoscopy has got some limitation in assessing operability in cases without extensive mobilization and also without the use of laparoscopic ultrasound. So in some cases palliative procedures was followed (Table 3). 
One 65-year male patient had a very peculiar clinical course. CT scan revealed thickened gallbladder wall with hepatoduodenal wall infiltration and upper GI endoscopy showed nodular elevation with multiple ulcers in stomach. Diagnostic laparoscopy and subsequent laparotomy showed a thickened gallbladder mass infiltrating antrum of stomach and adherent to omentum, thus antecolic GJ was done. Biopsy from the omental nodule suggested a granulomatous lesion with giant cell formation. Subsequent follow-up endoscopy after 4 wks. showed complete resolution of nodular lesions with ulcers of stomach.

After diagnostic laparoscopy in this small series of patients $(n=40), 8$ patients were diagnosed with disseminated disease, thus unnecessary laparotomy was avoided. Detail reasons for inoperability were shown in (Table 4). The surgical procedure was palliative in 8 patients, because of advanced disease with local infiltration or liver/peritoneal deposits (Fig. 4) and surgery was done in 23 patients with a curative intent.
(Fig. 5) shows the final outcome after diagnostic laparoscopy and subsequent laparotomy.

The average duration of the diagnostic laparoscopy was 25 mins (15-40 mins) and the average time for restoration of bowel movements was 3.1 days (1-6 days) in patients where open surgery was not done. The average duration of hospitalization was variable for those with disseminated disease 2 days (1-4 days) and those other open laparotomy cases where definitive procedures was done 9 days (5-14 days). One patient with stomach cancer had postoperative leak from the feeding jejunostomy site following ascites due to underlying cirrhosis of liver. The patient improved conservatively and feeding jejunostomy was removed on $25^{\text {th }}$ day. One patient with locally advanced rectum cancer developed severe postoperative bladder dysfunction, incontinence and urinary tract infections. Another patient with rectum cancer developed intestinal obstruction in the postoperative period, which was corrected surgically.

\begin{tabular}{|c|c|c|c|c|}
\hline GI Malignancy & Patient (N=106) & Mean Age (Range; Years) & Excluded (N=66) & Evaluable (N=40) \\
\hline Oesophagus & 7 & $60(55-83)$ & 6 & 1 \\
\hline Gallbladder & 16 & $59(56-74)$ & 11 & $5(1$, Benign) \\
\hline Stomach & 51 & $53(40-86)$ & 32 & 19 \\
\hline Colon & 6 & $61(36-70)$ & 2 & 4 \\
\hline Rectum & 11 & $58(27-74)$ & 5 & 1 \\
\hline Pancreas & 5 & $62(49-76)$ & 4 & 4 \\
\hline Periampullary & 10 & $57(36-78)$ & 6 & \\
\hline \multicolumn{2}{r}{} \\
\hline
\end{tabular}

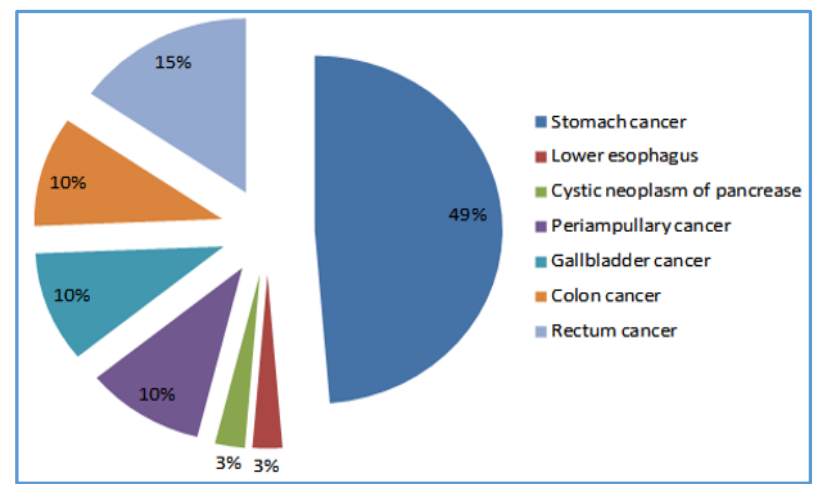

Fig. 1: Percentage of different GI Malignancy (n=40)

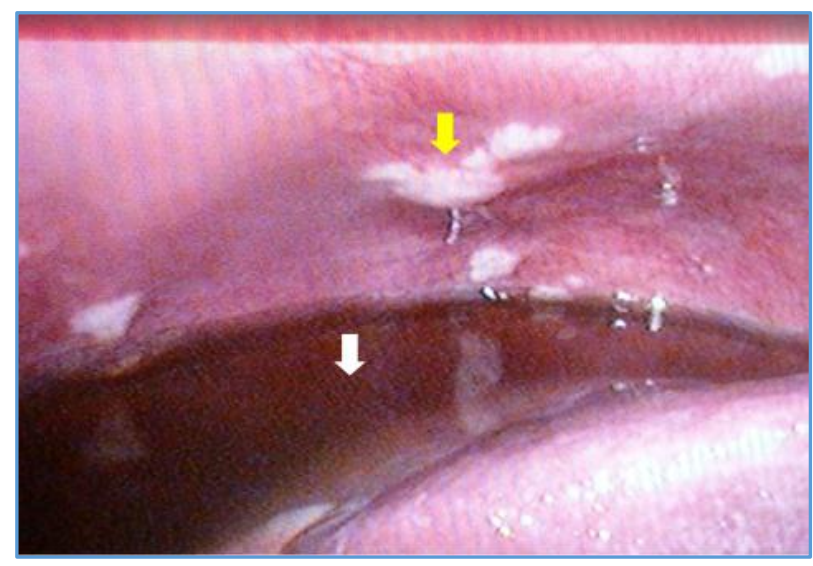

Fig. 2: Disseminated Disease with Multiple Peritoneal Deposits, Yellow Arrow Deposits, White Arrow Ascites

\begin{tabular}{|c|c|c|}
\hline All Benefits & $8 / 40$ & \\
\hline Stomach Cancers & 6 & \\
\hline Gallbladder Cancer & 2 & \\
\hline Stomach & 6 & \\
\hline GE Junction & Disseminated & No Procedure \\
\hline Prepyloric & Disseminated & No Procedure \\
\hline Linitis Plastica & Disseminated & No Procedure \\
\hline Linitis Plastic & $\begin{array}{l}\text { Deposits } \\
\text { falciparum }\end{array}$ & \\
\hline \multicolumn{3}{|c|}{ Body \& Lesser Curvature Serosal, Infiltration } \\
\hline & Lt. Lobe deposits & \\
\hline $\begin{array}{c}\text { Gallbladder } \\
\text { Cancer }\end{array}$ & 2 & \\
\hline \multirow[t]{2}{*}{ Gallbladder Cancer } & Disseminated & No Procedure \\
\hline & Disseminated & No Procedure \\
\hline \multicolumn{3}{|c|}{$\begin{array}{l}\text { (Disseminated-Multiple peritoneal, liver deposits with } \\
\text { ascites) }\end{array}$} \\
\hline \multicolumn{3}{|c|}{$\begin{array}{c}\text { Table 2: Benefits of Laparoscopy Avoiding } \\
\text { Unnecessary Laparotomy }\end{array}$} \\
\hline
\end{tabular}

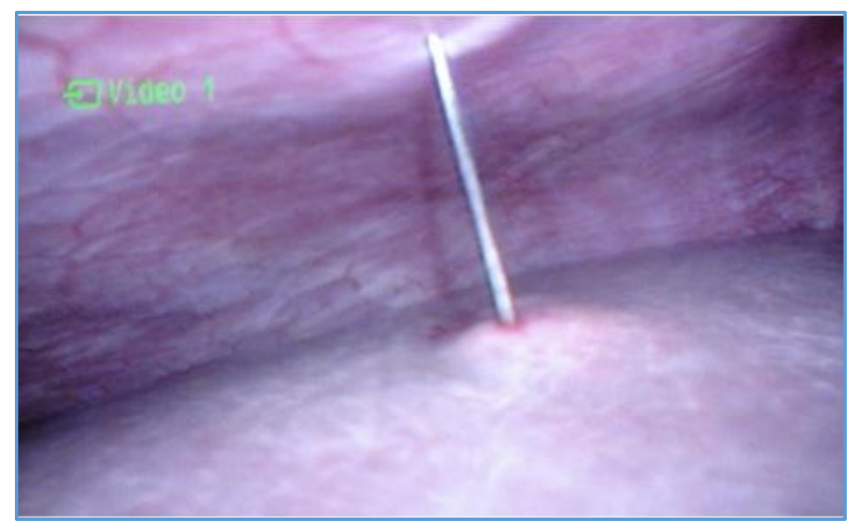

Fig. 3: Intraoperative FNAC of Doubtful Lesions 


\begin{tabular}{|c|c|c|}
\hline GI Malignancy & $\begin{array}{c}\text { Reasons for } \\
\text { Palliative Surgery }\end{array}$ & Number \\
\hline Stomach & $\begin{array}{c}\text { Local infiltrations to } \\
\text { deep margins of crura }\end{array}$ & 1 \\
\hline Stomach & $\begin{array}{c}\text { Nodular deposit to liver } \\
\text { and omentum }\end{array}$ & 1 \\
\hline Rectum & $\begin{array}{c}\text { Local infiltrations to } \\
\text { bladder serosa }\end{array}$ & 1 \\
\hline Rectum & $\begin{array}{c}\text { Local infiltrations to } \\
\text { posterior wall of vagina } \\
\text { with extensive nodal } \\
\text { disease }\end{array}$ & 1 \\
\hline Rectum & $\begin{array}{c}\text { Radial margin was } \\
\text { positive }\end{array}$ & 1 \\
\hline $\begin{array}{c}\text { Cystic neoplasm } \\
\text { of pancreas }\end{array}$ & $\begin{array}{c}\text { Significant } \\
\text { retropancreatic nodes }\end{array}$ & 1 \\
\hline Gallbladder & $\begin{array}{c}\text { Significant } \\
\text { pericholedochal-nodes }\end{array}$ & 1 \\
\hline $\begin{array}{c}\text { Gastro- } \\
\text { oesophageal } \\
\text { junction }\end{array}$ & $\begin{array}{c}\text { Positive oesophageal } \\
\text { margins on biopsy }\end{array}$ & 1 \\
\hline \multicolumn{2}{|r|}{ Table 3: Causes of Palliative Surgery } \\
\hline \multicolumn{2}{|c|}{} \\
\hline
\end{tabular}

\begin{tabular}{|c|c|}
\hline Status & Number \\
\hline Peritoneal metastasis & 7 \\
\hline Liver metastasis & 3 \\
\hline Ascites & 4 \\
\hline Extensive nodal diseases & 4 \\
\hline Local infiltration & 2 \\
\hline \multicolumn{2}{|c|}{ Table 4: Causes of Inoperability } \\
\hline
\end{tabular}
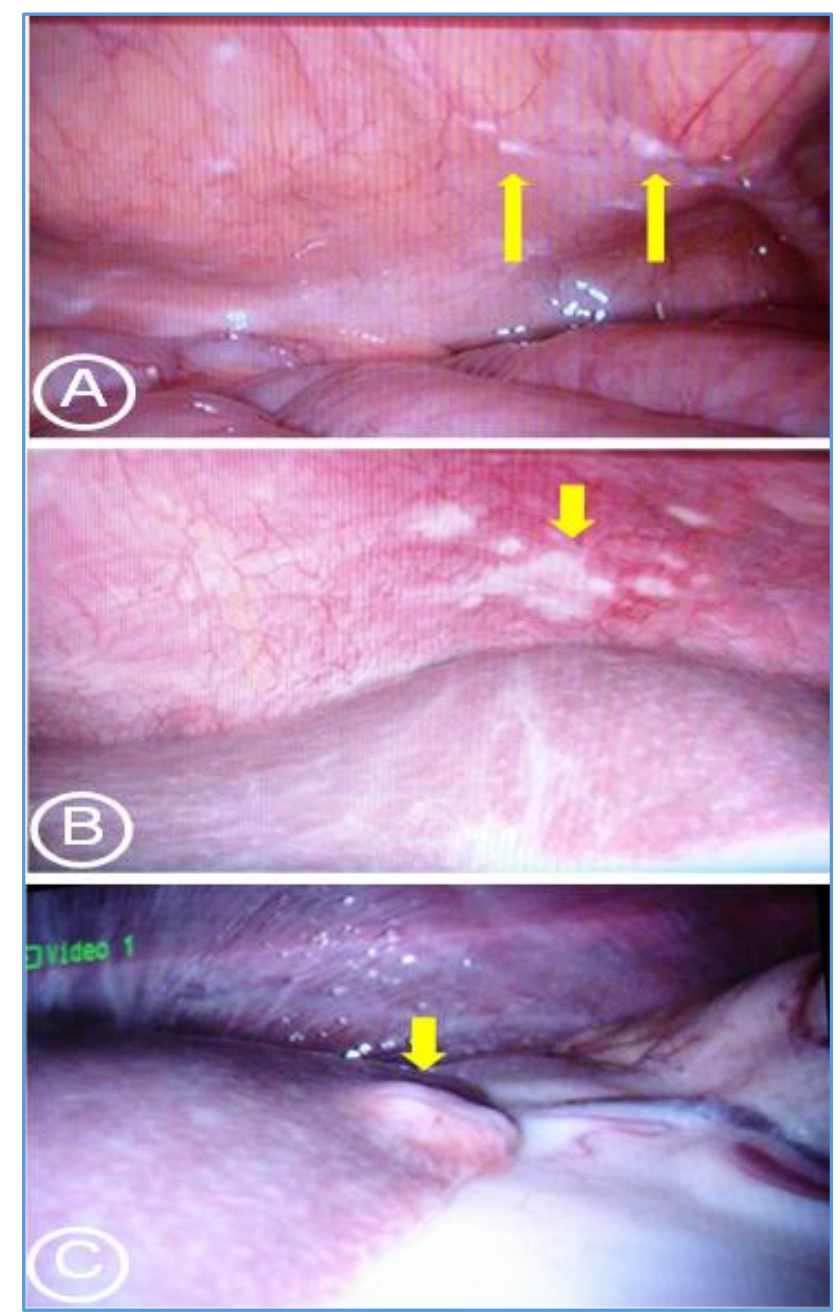

Fig. 4: Multiple Peritoneal Deposits A and B, Liver Nodule C

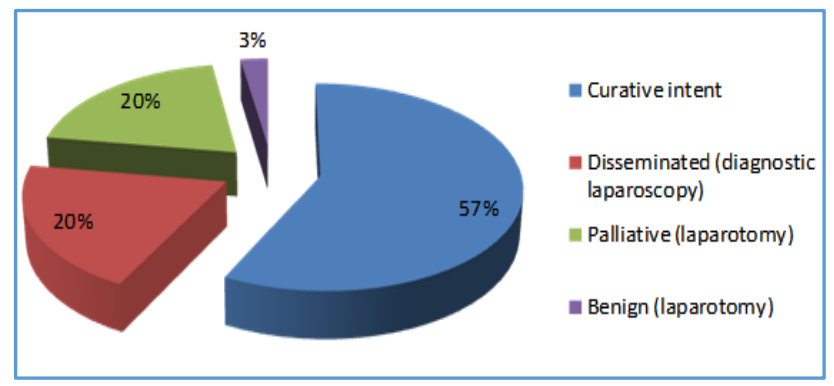

Fig. 5: Outcome after Diagnostic Laparoscopy and Subsequent Laparotomy

\section{DISCUSSION}

Several research reports have suggested that the laparoscopy is an important tool in the staging of abdominal malignancy.[11,12] Laparoscopic examination helps in many ways including direct visualizing the primary tumour, identify hepatic metastases, superior staging of liver tumours, preoperative staging and assessment of respectability of pancreatic cancer, diagnose regional nodal metastases, staging of carcinoma of the oesophagus and gastric cardia, and detect small-volume peritoneal disease unappreciated by other non-invasive staging modalities.[13-19] The present study evaluated the role of diagnostic laparoscopy in staging and assessing operability in GI malignancy. Out of total 40 patients, laparoscopy avoided $20 \%$ patients with unnecessary laparotomy. Diagnostic laparoscopy has the best utility in detecting peritoneal nodules and liver metastasis and all such were diagnosed in this present study.

Prospective multi-institutional studies revealed that noninvasive staging modalities like ultrasound, CT scan, MRI and endoscopic ultrasound plays an important role in the therapeutic approach of GI malignancies, but failed to identify $25 \%$ of metastatic disease, which was identified by laparoscopy.[20] Hemming et al[13] demonstrated that laparoscopic staging in intraabdominal malignancies is of great value and will prevent up to $36 \%$ of futile laparotomies.

Staging laparoscopy can range from simply inspecting the liver and peritoneum to extensive dissection, which may include lesser sac exploration and the use of laparoscopic ultrasound. Laparoscopic ultrasound defines the depth of tumour penetration, nodal involvement and occult liver metastasis. In our study maximum number of patients was of stomach carcinoma, in which unnecessary laparotomy was avoided in (6 out of 19) 31.57\% patients. Additional feeding jejunostomy was done in 2 patients. Unfortunately, we had the limitation of the use of both laparoscopic ultrasound and endoscopic ultrasound. In one of the early studies undetected metastasis disease in gastric cancers patients were found in $13 \%$ to $57 \%$ initially staged by conventional modalities and exploratory laparotomy was avoided in over $20 \%$ patients. ${ }^{[21]}$ These prospective studies showed staging accuracy of laparoscopy is $90 \%$ vs. $70-80 \%$ in conventional imaging. Burke et al[22] published their study of 110 gastric cancer patients who underwent laparoscopy, which enabled them to exclude $22 \%$ of these patients for further surgical intervention due to identification of occult metastasis. Earlier prospective study found that staging laparoscopy in oesophageal and gastric cancer patients reduced the rate of needless laparotomy from $25 \%$ to $12 \%$.[23] The addition of laparoscopic ultrasound further reduced this rate to $9 \%$. 
Further, Tsioulias et al[8] demonstrated in his study that laparoscopy discovered peritoneal metastasis in $17 \%$ of patients that were not seen by other modalities.

In this study there were total 10 cases of colorectal malignancy, 4 patients of colon cancer and 6 of rectum cancer. None of the patients was found unresectable on diagnostic laparoscopy, although the procedure was palliative in 3 cases of rectal cancer due to lateral wall and posterior vaginal wall infiltration and liver nodules. Muntean et al[24] found in his study that unnecessary laparotomy was avoided in 36 of the 99 patients $(36.4 \%)$ without distant metastases on imaging pre-therapeutic staging and staging laparoscopy avoids unnecessary laparotomies and changes the therapeutic plan in a significant number of patients.

Pancreatic cancer often presents with advanced disease with curative resection possible in only $5 \%$ to $15 \%$ of patients. Jiminez et al[25] found that laparoscopy diagnosed unsuspected metastases in $31.2 \%$ of patients with pancreas cancer, thus avoiding non-therapeutic laparotomy. Other studies have indicated that staging laparoscopy can detect unresectable disease in $20 \%$ to $48 \%$ of patients found resectable by CT scan.[26] Thus, laparoscopy must be performed in all pancreatic cancer patients prior to curative surgery. In our study, we found one patient with large cystic neoplasm of pancreas with significant retropancreatic nodes. So, only palliative distal pancreatectomy with splenectomy was completed. Although limited in our setup of laparoscopic ultrasound has got significant role in assessing resectability. Study by Schachter and Colleagues demonstrated a change in surgical intervention in $36 \%$ of patients with avoidance of unnecessary laparotomy in 31\%.[27] Similarly, cytological examination of peritoneal washing obtained at the time of laparoscopy has been suggested to enhance the sensitivity of staging laparoscopy.[28]

Till date accurate staging for hepatobiliary malignancy is important, as there is no role for laparotomy or palliative surgery in the presence of metastatic disease. Montorsi.[29] demonstrated in one prospective study involving 60 patients that laparoscopic procedure detected additional tumour nodule in 11 out of 15 patients, and this changed the plan of management. Study by D'Angelica.[30] demonstrated in hilar cholangiocarcinoma and gallbladder cancer at MSKCC, New York, that laparoscopy procedures identified 84 inoperable cases out of 153 , increasing resectability from $62 \%$ to $78 \%$. In our study of 4 patients of gallbladder cancer, disseminated disease was found in 2 patients. In another patient with multiple significant pericholedochal nodes procedure was only limited to palliative radical cholecystectomy. Moreover, Lo et al[31] demonstrated in his study that laparoscopy and laparoscopic ultrasound were both able to evaluate disease resectability, thus aid in selection of patients who would benefit from either laparoscopic resection or local ablative therapy and/or formal hepatectomy.

In the literature review the outcome after various preoperative imaging and diagnostic laparoscopy was analysed. Although not done in our setup, EUS is more accurate than CT for staging pancreatic malignancies including predicting vascular invasion and local resectability.[32] Similarly, in the review article, Lightdale et al observed that EUS has been invariably more accurate than computed tomography for $\mathrm{T}(80-90 \%)$ and $\mathrm{N}(75 \%)$ staging, but EUS is limited for staging distant metastases. ${ }^{[33]}$ In a study of different imaging modalities in upper GI malignancy,
Mortensen et al observed that accuracy of EUS+LUS identified all non-resectable patients and the sensitivity of CT+US, laparoscopy and EUS were $14 \%, 36 \%$ and $79 \%$, respectively.[34]

The success of diagnostic laparoscopy has its own limitations, particularly in identifying local infiltration and nodal disease. In 2 patients with gastro-oesophageal junction cancer and rectum cancer, the proximal oesophageal margins and also radial margins were positive. Recently, introduction of laparoscopic ultrasound in the armamentarium of minimally invasive surgery resulted in identification of occult metastasis in solid organs including liver, peritoneum, etc. Using laparoscopic tool, even lesions smaller than $1 \mathrm{~cm}$ can be identified, biopsied and ablated easily. Laparoscopy has been suggested to prevent $10-44 \%$ of patients from having an unnecessary laparotomy by identifying those with unresectable disease not identified by imaging.[35]

\section{CONCLUSION}

Different GI tract cancers have different peculiar biological behaviour, so applying diverse modality to study various GI cancers and therapeutic approach may be questionable to surgeons nowadays. Diagnostic laparoscopy in GI malignancy appears to be a safe, painless, faster recovery, cost-effective means of directing appropriate therapy and also avoids unnecessary laparotomies. This has been associated with decreased morbidity and earlier plan for neoadjuvant treatment.

The main area where laparoscopy scores over imagelogy is in identifying peritoneal and surface lesions of various organs inside the peritoneal cavity and provision for taking biopsy under vision. We know that our sample size is small, and each subtype is not evaluated extensively. However, our study revealed that diagnostic laparoscopy can be performed just before the planned surgery or as a separate diagnostic procedure.

\section{ACKNOWLEDGMENT}

We thank people from Department of Surgery and Department of Radiology, Kalinga Institute of Medical Sciences (KIMS) those who helped us to carry out this study.

\section{REFERENCES}

1. Van Dijkum EJN, de Wit LT, van Delden OM, et al. The efficacy of laparoscopic staging in patients with upper gastrointestinal tumours. Cancer 1997;79(7):1315-9.

2. Conlon KC, Minnard EA. The value of laparoscopic staging in upper gastrointestinal malignancy. The Oncologist 1997;2(1):10-17.

3. Nair CK, Kothari KC. Role of diagnostic laparoscopy in assessing operability in borderline resectable gastrointestinal cancers. J Minim Access Surg 2012;8(2):44-49.

4. Siewert JR, Sendler A, Dittler HJ, et al. Staging gastrointestinal cancer as precondition for multimodal treatment. World J Surg 1995;19(4):168-77.

5. Nghiem HV, Freeny PC. Radiologic staging of pancreatic adenocarcinoma. Radiol Clin North Am 1994;32(1):71-9.

6. Reeders JW, Bartelsman JF. Radiological diagnosis and preoperative staging of oesophageal malignancies. Endoscopy 1993;25(1):10-27. 
7. Lillemoe KD. Current management of pancreatic carcinoma. Ann Surg 1995;221(2):133-48.

8. Tsoulias GJ, Wood TF, Chung $\mathrm{MH}$, et al. Diagnostic laparoscopy and laparoscopic ultrasonography are essential for staging intra-abdominal neoplasms. Gastroenterology 2001;120(5):A482.

9. Bemelman WA, van Delden OM, van Lanschot JJB, et al. Diagnostic laparoscopy combined with laparoscopic ultrasonography influences reoperative staging of malignancies involving the oesophagus. J Am Coll Surg 1995;181:421-5.

10. Gouma DJ, De Wit LT, van Dijkum NE, et al. Laparoscopic ultrasonography for staging of GI-malignancy. Scand J Gastroenterol 1996;218:43-9.

11. Conlon KC, Rusch VW, Gillern S. Laparoscopy: an important tool in the staging of malignant pleural mesothelioma. Ann Surg Oncol 1996;3(5):489-94.

12. Conlon KC, Doughtery E, Klimstra DS, et al. The value of minimal access surgery in the staging of patients with potentially resectable peri-pancreatic malignancy. Ann Surg 1996;223(2):134-40.

13. Hemming AW, Nagy AG, Scudamore $\mathrm{CH}$, et al. Laparoscopic staging of intraabdominal malignancy. Surg Endosc 1995;9(3):325-8.

14. Babineau TJ, Lewis D, Jenkins RL, et al. Role of staging laparoscopy in the treatment of hepatic malignancy. Am J Surg 1994;167:151-4.

15. Bartlett DL, Conlon KC, Gerdes H, et al. Laparoscopic ultrasound: the best pretreatment staging modality in gastric adenocarcinoma? Case report. Surgery 1995;118(3):562-6.

16. Bemelman WA, De Wit LT, van Delden OM, et al. Diagnostic laparoscopy combined with laparoscopic ultrasonography in staging of cancer of the pancreatic head region. Br J Surg 1995;82(6):820-4.

17. Hann LE, Conlon KC, Hilton S, et al. Laparoscopic grey scale and duplex Doppler ultrasound: application in management of pancreatic cancer. (AIUM abstract) 1996.

18. Eubanks S. The role of laparoscopy in diagnosis and treatment of primary or metastatic liver cancer. Sem Surg Oncol 1994;10:404-10.

19. Nord HJ, Boyd WP. Diagnostic laparoscopy. Endoscopy 1992;24:133-7.

20. Krasna MJ, Reed CE, Nedzwiecki D, et al. CALGB 9380: a prospective trial of the feasibility of thoracoscopy/laparoscopy in staging oesophageal cancer. Ann Thorac Surg 2001;71(4):1073-9.

21. D’Ugo DM, Pende V, Persiani R, et al. Laparoscopic staging of gastric cancer: an overview. J Am Coll Surg 2003;196(6):965-74.
22. Burke EC, Karpeh MS, Conlon KC, et al. Laparoscopy in the management of gastric adenocarcinoma. Ann Surg 1997;225(3):262-7.

23. Smith A, Finch MD, John TG, et al. Role of laparoscopic ultrasonography in the management of patients with oesophagogastric cancer. Br J Surg 1999;86(8):1083-7.

24. Muntean V, Oniu T, Lungoci C, et al. Staging laparoscopy in digestive cancers accuracy and impact on therapy. J Gastrointestinal Liver Dis 2009;18(2):189-95.

25. Jiminez RE, Warshaw AL, Rattner DW, et al. Impact of laparoscopic staging in the treatment of pancreatic cancer. Arch Surg 2000;135(4):409-14.

26. Reddy KR, Levi J, Livingstone A, et al. Experience with staging laparoscopy in pancreatic malignancy. Gastrointest Endosc 1999;49(4 Pt 1):498-503.

27. Schachter PP, Avin Y, Schimonova M, et al. The impact of laparoscopy and laparoscopic ultrasonography on the management of pancreatic cancer. Arch Surg 2000;135(11):1303-7

28. Jimenez RE, Warshaw AI, Fernandez-del C. Laparoscopy and peritoneal cytology in staging of pancreatic cancer. J Hepatobil Pancreat Surg 2000;7:15-20.

29. Montorsi M, Santambrogio R, Bianchi $P$, et al. Laparoscopy with laparoscopic ultrasound for pretreatment staging of hepatocellular carcinoma: a prospective study. J Gastrointest Surg 2001;5(3):312-5.

30. D'Angelica M, Fong Y, Weber S, et al. The role of laparoscopy in hepatobiliary malignancy: prospective analysis of 401 cases. Ann Surg Oncol 2003;10(2):183-9.

31. Lo CM, Fan ST, Liu CL, et al. Determining resectability for hepatocellular carcinoma: the role of laparoscopy and laparoscopic ultrasonography. J Hepatobiliary Pancreat Surg 2000;7(3):260-4.

32. Gress FG, Hawes RH, Savides TJ. Role of EUS in the preoperative staging of pancreatic cancer: a large singlecenter experience. Gastrointest Endosc 1999;50(6): 786-91.

33. Lightdale CJ, Kulkarni KJ. Role of ultrasonography in the staging and follow up of oesophageal cancer. Journal of clinical oncology 2005;23(20):4483-9.

34. Mortensen MB, Scheel-hincke JD, Madsen MR, et al. Combined endoscopic ultrasonography and laparoscopic ultrasonography in the pre-therapeutic assessment of resectability in patients with upper gastrointestinal malignancy, Scandinavian. Journal of Gastroenterology 1996;31(11):1115-9.

35. Doucas H, Sutton CD, Zimmerman A, et al. Assessment of pancreatic malignancy with laparoscopy and intraoperative ultrasound. Surg Endosc 2007; 21(7):1147-52. 